\title{
New Interesting Findings in Palaeontology
}

Anacardiaceous fossil fruit is recorded for the first time from Neyveli lignite deposits (Miocene) of Tamil Nadu (Agarwal and Ambawani, 2008, Jour. Pal. Soc. India, v.53(2), pp.215-220). It is carbonized small fossil fruit (drupe) belonging to family Anacardiaceae having bilaterally convex with prominent dehiscence suture.

Relict benthic foraminiferal assemblage recorded off west coast of Myanmar recently (Panchang et al. 2008, Jour. Pal. Soc. India, v.53(2), pp.185-195) and their signature confirm that the existence of fossil patch reefs in the region, which were not recorded earlier. A conceptual framework is proposed by the authors to explain the proliferation of coral patches at different depths during different times in the geological past. On the basis of faunal ecology and chronology, for the first time a sea level curve for the past 16000 radiocarbon years is proposed for the west coast of Myanmar. This study suggests episodic sea level rise in the region. A comparison of this sea level curve with the ones proposed for the east and west coasts of India indicates that in addition to the global Holocene sea level rise, tectonic vertical displacement is the cause of the destruction of the soft coral patches off west coast of Myanmar.

Eocene faulting in the subsurface section near Sam, Jaisalmer, Rajasthan is identified based on foraminiferal evidence (Kaila et al. 2008, Jour. Pal. Soc. India, v.52(2), pp.1969-1975). The ages indicated by the planktic and larger foraminiferal species confirm the stratigraphic inversion due to fault in the subcrops. - UBM 